\title{
Renewable Energy Types
}

\author{
Nada Kh. M. A. Alrikabi
}

\begin{abstract}
The rapid increase in energy consumption particularly in the past several decades has raised fears of exhausting the globe's reserves of petroleum and other resources in the near future. The huge consumption of fossil fuels has caused visible damage to the environment in various forms. Approximately $90 \%$ of our energy consumption comes from fossil fuels. Due to industrializations and population growth our economy and technologies today largely depend upon natural resources, which are not replaceable.
\end{abstract}

Index Terms-Renewable energy, solar energy, sustainability, wind energy.

\section{INTRODUCTION}

The United States currently relies heavily on coal, oil, and natural gas for its energy. Fossil fuels are nonrenewable, that is, they draw on finite resources that will eventually dwindle, becoming too expensive or too environmentally damaging to retrieve. Every year human activity dumps roughly 8 billion metric tons of carbon into the atmosphere, 6.5 billion tons from fossil fuels and 1.5 billion from deforestation [1] The huge consumption of fossil fuels has caused visible damage to the environment in various forms.. It creates lot of environment problem and finally our ecological cycle will be affected. The energy industry needs to get more from existing fields while continuing to search for new resources. Due to technological advancement vehicles are made with improved fuel efficiency and also perfect hybrid vehicle are made. Also the improvements are needed so that wind, solar and hydrogen can be playing more valuable sources in the energy field. The many types of renewable energy resources-such as wind and solar energy-are constantly replenished and will never run out that is one benefit .Most renewable energy comes either directly or indirectly from the sun. Sunlight, or solar energy, can be used directly for heating and lighting homes and other buildings, for generating electricity, and for hot water heating, solar cooling, and a variety of commercial and industrial uses.

The another advantage using renewable resources is that they are distributed over a wide geographical area, ensuring that developing regions have access to electricity generation at a stable cost for the long-term future. The sun's heat also drives the winds, whose energy, is captured with wind turbines. Then, the winds and the sun's heat cause water to evaporate. When this water vapor turns into rain or snow and flows downhill into rivers or streams, its energy can be captured using hydroelectric power.

Along with the rain and snow, sunlight causes plants to

Manuscript received January 29, 2013; revised June 29, 2013.

Nada Kh. M. A. Alrikabi is with Baghdad University, Iraq (email: nada715kh@yahoo.com). grow. The organic matter that makes up those plants is known as biomass. Biomass can be used to produce electricity, transportation fuels, or chemicals. The use of biomass for any of these purposes is called bio energy.

Hydrogen also can be found in many organic compounds, as well as water. It's the most abundant element on the Earth. But it doesn't occur naturally as a gas. It's always combined with other elements, such as with oxygen to make water. Once separated from another element, hydrogen can be burned as a fuel or converted into electricity.

Not all renewable energy resources come from the sun. Geothermal energy taps the Earth's internal heat for a variety of uses, including electric power production, and the heating and cooling of buildings. And the energy of the ocean's tides come from the gravitational pull of the moon and the sun upon the Earth. In fact, ocean energy comes from a number of sources. In addition to tidal energy, there's the energy of the ocean's waves, which are driven by both the tides and the winds. The sun also warms the surface of the ocean more than the ocean depths, creating a temperature difference that can be used as an energy source. All these forms of ocean energy can be used to produce electricity [2].

\section{RENEWABLE ENERGY IS IMPORTANT BECAUSE OF THE BENEFITS IT PROVIDES}

\section{A. Environmental Benefits}

Renewable energy technologies are clean sources of energy that have a much lower environmental impact than conventional energy technologies.

\section{B. Energy for Our Children's Children (Sustainability)}

Renewable energy will not run out. Ever, other sources of energy are finite and will some day be depleted.

\section{Jobs and the Economy}

Most renewable energy investments are spent on materials and workmanship to build and maintain the facilities, rather than on costly energy imports. Renewable energy investments are usually spent within the United States, frequently in the same state, and often in the same town. This means your energy dollars stay home to create jobs and fuel local economies, rather than going overseas. Meanwhile, renewable energy technologies developed and built in the United States are being sold overseas, providing a boost to the U.S. trade deficit.

\section{Energy Security}

After the oil supply disruptions of the early 1970s, our nation has increased its dependence on foreign oil supplies instead of decreasing it. This increased dependence impacts more than just our national energy policy [3]. 


\section{AVAilability of ReNEWABLE ENERGy ResourCES}

Renewable Energy sources are not depleted, and it is distributed over a wide geographical area, these resources are quickly renewed through natural process. It won't create any environmental pollution problems. The main advantage of using renewable resource is it is available throughout the year. By an one time investment we can drew energy for many decades without affecting the environment.

\section{A. Solar Energy}

Solar Energy has the greatest potential for providing clean, safe, and reliable power. The solar energy falling on the Earths continents is more than 200 times the total annual commercial energy currently being used by humans [4]. The government started solar power adoption with subsidies. A consumer who installs a solar panel array on a house can sell surplus energy to the local utilities. The solar panel cost, reduced to $50 \%$, which would make solar Powered Electricity cost comparable with other types of fuel, is possible within the next decade [5]. Solar Energy can be classified as two types 1 . Passive solar and 2. Active solar. Passive solar energy is making direct and indirect use of thermal energies from the sun. Indirect use of Energy is possible only in building (or) structures (as shown in Fig. 1). A southern exposure of a building guarantees the maximum exposure of the sun's rays. Special metal leaf covering over windows and roofs can block out the sun during the summer months. Special thermal solar collectors can circulate water through the collection unit that collect the sun's thermal energy for the purpose of heating the water for use [6]. Active Solar Energy is the use of the sun's Electro magnetic radiation in generating Electrical Energy. Generally semiconductor silicon Boron solar chips are used for this. The problem of these chips one that they have low Efficiency ratio and can only be used in supplying Energy needs of small devices (i.e. calculators, watches, radio etc.)as shown in Fig.2 .

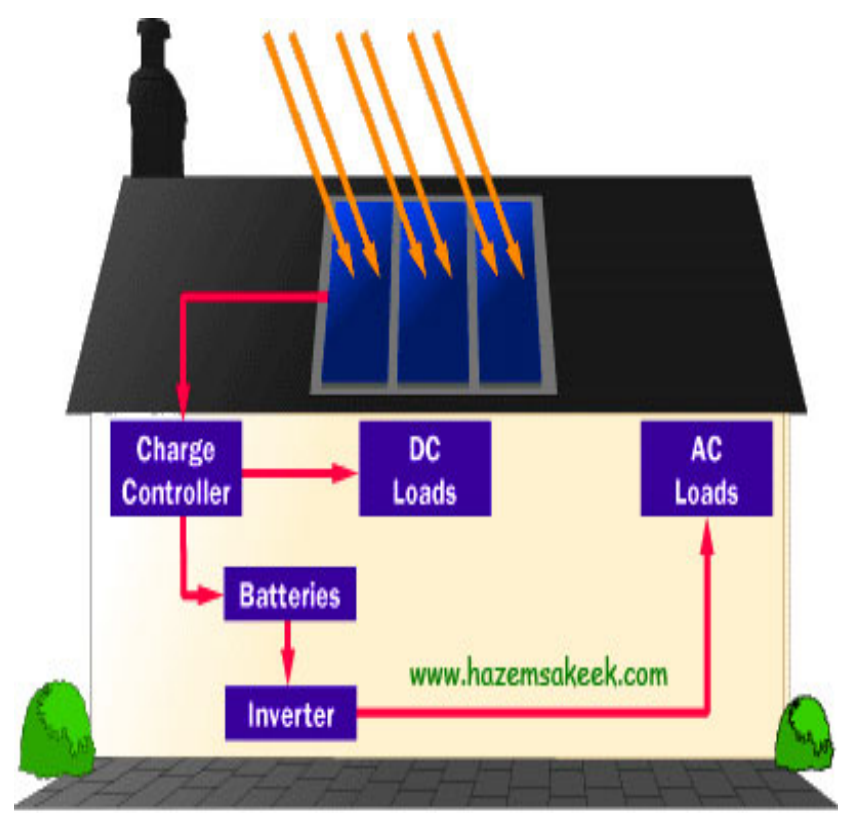

Fig. 1. Solar energy mechanism at the unit

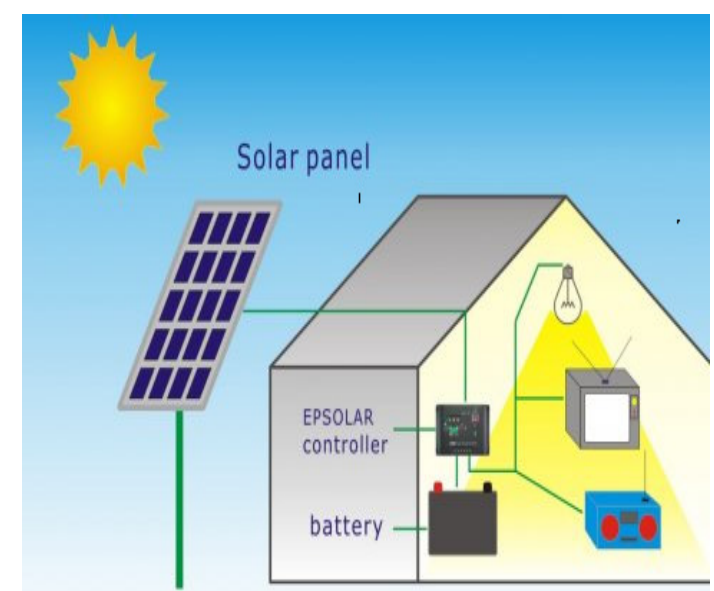

Fig. 2. Solar energy at small unit

\section{B. Wind Energy}

Wind, ultimately driven by atmospheric air, is just another way of collecting Energy. Sun also heats the atmosphere, which produces wind. It works on cloudy days and Rainy season also. The location of wind turbines is a very important factor, which influences the performance of the machine. The windmills are generally located at the top of a tower to heights approximately $30 \mathrm{~m}$. To avoid turbulence from one turbine affecting the wind flow at others it is located at 5-15 times blades diameter. Windmills are working both in horizontal axis and vertical axis.

The basic mechanics of the two systems are similar. Wind passing over the blades is converted in to mechanical power, which is fed through transmission to an electrical generator. Wind turbines will not work in winds below 13 $\mathrm{km}$ an hour. They work best where the wind speed averages $22 \mathrm{~km}$ an hour. The majority of wind turbines produced at the present time are horizontal axis turbine with three blades, 15-30 m diameter, producing 50-350 Kw of Electricity. Wind energy produces no air or water pollution, involves no toxic or hazardous substances, and poses no threat to public safety.

\section{Biomass Energy}

Biomass is the most important source for energy productions supplied by agriculture. Effective harnessing of bio-energy can energize entire rural milieu in a country like India where nature offers various types of biomass. This energy is also available in the form of biodegradable waste, which is the rejected component of available biomass [7]. Biomass energy refers to fuels made from plants and animal wastes. The Biomass resource is, organic matter in which the energy of sunlight is stored in chemical bonds. When the bonds between carbon, hydrogen and oxygen molecules are broken by digestion, combustion (or) decomposition these substances release stored energy. Biomass energy is generated when organic matter is converted to Energy. In alcohol fermentation, the starch in organic matter is converted to sugar by heating. This sugar is then fermented and finally ethanol is distiller and then blended with another fuel. An aerobic digestion converts biomass, especially waste product such as municipal solid waste and market waste. In this process, the facultative bacteria breakdown the organic material in the absence of oxygen and produce 
methane and carbon dioxide. Bioconversion is a nonpolluting, environmentally feasible and cost effective process [8]. The effluent and digester residues are rich in nitrogen and phosphorus, which can be recycled back to the soil as a fertilizer [9]. By using this method we can derive $70 \%$ of the energy. The biomass is mixed with water and stored in an airtight tank. The organic wastes (Municipal Solid Waste) are collected separately and dried natural method and shredded to the maximum particle size of $2-4$ $\mathrm{mm}$. This was stored in a plastic container at room temperature and was characterized and it was used during all anaerobic digestion treatment. Domestic sewage was collected from a college campus before disposal. It was used in all anaerobic digestion experiment for diluting the feedstock to achieve the required total solids concentration for the present investigation. Experiments were carried out in 5 lit. Capacity batch type reactor operating in semi continuous mode with daily feeding. The digester was operated at room temperature at a constant hydraulic retention time of 25 days with different organic loading rate. To start with, the digester was initiated by charging with 2.75 lit. of feed stocks ( $2 \% \mathrm{TS})$ along with 2 lit. of feed sludge. The digester was maintained anaerobic ally and stabilization was to take place for two weeks. During this stabilization period, $\mathrm{pH}$ was maintained in the range of 6.5 to 7.5 by adding sodium hydroxide. The $\mathrm{pH}$ and gas production were measured every day. It was found that the maximum biogas production is $0.36 \mathrm{~m} 3 / \mathrm{kg}$ of $\mathrm{VS}$ added/day at the optimum organic loading rate of $2.9 \mathrm{~kg}$ of $\mathrm{VS} / \mathrm{m} 3 / \mathrm{d}$.

In Chennai the government set up a power plant using vegetable waste as fuel. Daily 40 tones of market waste is going to be used for the power plant. The power plant will generate about 4800 units of electricity/day. The gas comprises $65 \%$ of methane and $35 \%$ of carbon di oxide, and is transferred into a gasholder and finally electrical energy is produced. The power generated from the plant will be sold at Rs.3.15/unit

\section{Tidal Power}

Oceans cover Two Thirds of the Earth's surface. This water is vast reservoir of renewable energy. India is naturally located in seashore side and covered 3 sides by sea. The movement of the water at the coastal front in kinetic energy that can be converted into Electrical energy. The energy spread out along the thousand of $\mathrm{km}$ of coasts, in favorable location, the energy density can average 65 $\mathrm{MW} / \mathrm{mile}$ of coastline an amount which can lead to economical wave generated Electricity. The cheapest method to draw tidal power is that the oscillating water columns use the force of waves entering a fixed device to generate Electricity. The waves entering the anchored compress air in a vertical pipe. This compressed air can be used to simply derive a turbine generator producing Electricity. The main problem of wave power plants is cyclone and severe storms. During this period the plant is not working.

\section{E. Geothermal Energy}

Geothermal energy is the heat from the Earth. It's clean and sustainable. Resources of geothermal energy range from the shallow ground to hot water and hot rock found a few miles beneath the Earth's surface, and down even deeper to the extremely high temperatures of molten rock called magma.

Almost everywhere, the shallow ground or upper 10 feet of the Earth's surface maintains a nearly constant temperature between $50^{\circ}$ and $60^{\circ} \mathrm{F}\left(10^{\circ}\right.$ and $\left.16^{\circ} \mathrm{C}\right)$. Geothermal heat pumps can tap into this resource to heat and cool buildings. A geothermal heat pump system consists of a heat pump, an air delivery system (ductwork), and a heat exchanger-a system of pipes buried in the shallow ground near the building. In the winter, the heat pump removes heat from the heat exchanger and pumps it into the indoor air delivery system. In the summer, the process is reversed, and the heat pump moves heat from the indoor air into the heat exchanger. The heat removed from the indoor air during the summer can also be used to provide a free source of hot water [10].

\section{ENVIRONMENTAL PROBLEMS IN NON-RENEWABLE ENERGY RESOURCES}

Fossil fuels are coal; oil and natural gas, have originated from the decomposition of organic matter in or on the Earth. Coal is the worst offender among fossil fuels in terms of $\mathrm{CO}_{2}$ per unit of energy generated. Industrialized countries generate $20 \%$ to $30 \%$ of their energy from coal. Petroleum is derived from rich organic molecules in the sediments form. It emits sulphur contents and carbon monoxide and finally leads Acid rain. Natural gas is combustible mixture of methane and other hydrocarbons. Methane is highly corrosive one. The fossil fuels are producing following gaseous pollutants in the atmosphere.

\section{A. Carbon Dioxide}

Carbon Dioxide is responsible for $55 \%$ of global warming. The main sources are fossil fuel burning (77\%) and deforestation $(23 \%)$. The atmospheric Carbon di-oxide already presents nearly a $30 \%$ change in the world. Ultimately, this could increase the average global temperature by about $1^{\circ}-5^{\circ} \mathrm{C}$. Every year the average global surface temperature rises approximately $0.3^{\circ}-0.6^{\circ} \mathrm{C}$. The Nitrogen oxides are responsible for about $35 \%$ of acid rain [3]. Methane is responsible for about $20 \%$ of the green house effect. This is mainly emitted from burning of coal and natural gas leaks, natural gas associated with oil production and spillage of petrol. In Thermal power plants the coolant water is discharged into rivers (or) lakes. The water body suddenly increases the temperature and losing its oxygen holding capacity i.e., Dissolved oxygen is reduced, so it is directly affecting the aquatic organisms [7].

\section{EXISTING AVAILABLE RENEWABLE RESOURCES IN IRAQ}

In limited available technology and economical consideration to trap and store the renewable energies when we are in abundant supply in the area where other have to concentrate much. The production of fuel increases.

That alternative energy sources in Iraq is limited use and production.The reason is the presence of oil and the lack of 
environmental awareness. And a few investment in the field of renewable energy.

The types of renewable energy in Iraq are hydropower dams and reservoirs (LIMITED) .Solar energy for street lighting (as shown in picture bellow F1g. 3). And wind power projects under implementation, but in limited locations depending on the potential availability of wind and these sites on the west side, the south-west and north-west of the country and near the coastal areas (specific space in Iraq in the southern city of Basra) [11].

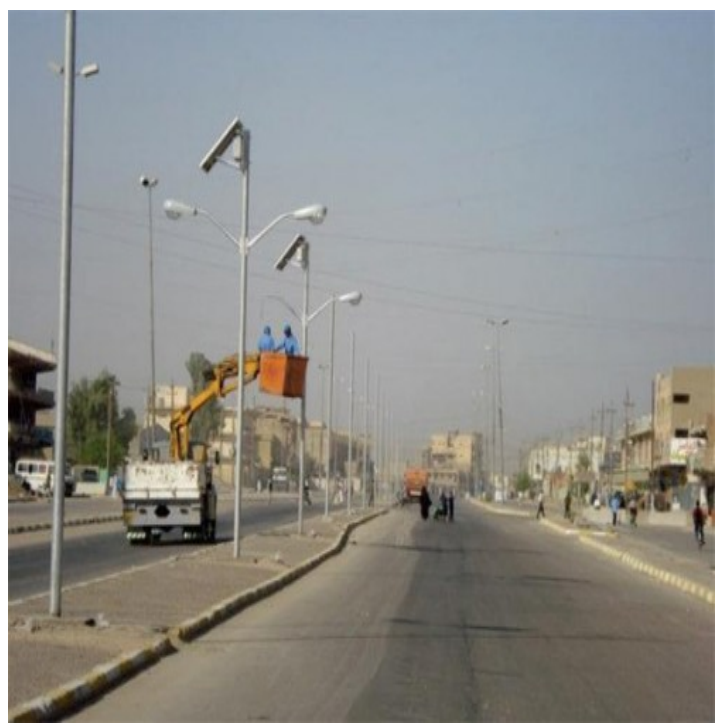

Fig. 3. Solar energy uses in Iraq

\section{ECONOMICAL BENEFITS}

Problems with renewable energy sources are nonavailability at a reasonable cost, limited supplies and lack of cost Effective means for capturing and concentrating the renewable Energy. By Effective steps to eliminate these importing of fossil fuel (oil and Natural gases) can be minimized the country's economy will increase [8]. The production cost of renewable source is reduced by subsidies. For some years, the World Bank has been sold Electricity in developing countries at an average only $40 \%$ of the cost of its production. The government by introducing subsidies in the form of relaxing duties, taxes and installation charges, the prices can be drastically reduced and it will came equal to fossil fuel rate [9].

\section{A. World Energy Conservation}

Predicted estimation about the rate of utilization of energy resources shows that the coal deposits will deplete within the next 200 to 300 years and petroleum deposits will deplete in next few decades. Now, the world is looking for alternate energy resources. Hence, it is necessary to encourage and emphasize the research and development activities covering abroad spectrum of possible renewable resources, as their contributions are substantial. Renewable Energy sources are not depleted. These resources are quickly renewed through natural process. It won't create any environmental pollution problems.

The main advantage of using renewable resource is it is available throughout the year.

By a one time investment we can drew energy for many decades without affecting the environment. Successful implementation of renewable energy sources our country economy is increased [1].

\section{CONCLUSION}

The renewable sources are cost effective, user-friendly, so that they can easily beat the fossil fuels. By promoting renewable energy sources we can avoid, Air pollution, soil pollution and water pollution. Country's Economy will increase. Throughout the year these sources are available without affecting the Environment

\section{REFERENCES}

[1] I. G. Malkivia-pyh and Y. A. Pyh, Sustainable energy Resources, Technology and Planning, WIT Press, pp. 24-29, Boston, 2002.

[2] T. Tieten and L. Lewise, Environmental and Natural Resources Economic"s, $8^{\text {th }}$ edition, pp. 59-62, 2000.

[3] D. E. Booth, The Environmental Consequences of Growth, London and New York, pp. 88-90, 1998.

[4] Ashokverghese, "New and Renewable Energy Resources," Proceedings of International conference on Alternate Energy resources, Asian Institute of Technology, Thailand, pp. $403-$ 410,1998 .

[5] J. H. Gibbons et.al, "Strategies for energy use," vol. 261, pp. 136-143, 1989.

[6] W. R. Cline, The Economics of Global Warming, Washington D. C, pp. 45-55, 1992.

[7] Popular Mechanics Magazine, pp. 10- 12, September 2005.

[8] Time Magazine, pp. 32-33, August 2005.

[9] Journal of Innovations in Renewable Energy, vol. 2, pp. 24-25, June 2005.

[10] Renewable Energy World. [Online]. Available: http://www.renewableenergyworld.com/rea/tech/geothermal-energy, 2012.

[11] National Geographic Magazine, pp. 35-40, August 2005.

[12] N. Khaleefah and S. Jabir, "The use of solid waste to produce energy," Proc.3ed Conference of Planning, Dohok \& Dortmund University, pp. 12-15, 2012..

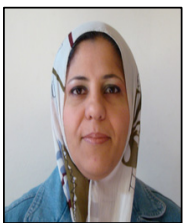

Nada Kh. M. A. Alrikabi was born in Iraq in1971. She has $\mathrm{PhD}$ in Urban \& environmental planning, 2005. She is now working in Baghdad University. She is the assistant Professor in the Institute of Urban \& regional planning for post graduate studies. 